\title{
Mixed surface chemistry on carbon fibers to promote adhesion in epoxy and PMMA polymers.
}

James D. Randall, ${ }^{a}$ Daniel J. Eyckens, ${ }^{b}$ Essi Sarlin, ${ }^{c}$ Sarianna Palola,,${ }^{c}$ Gunther G. Andersson, ${ }^{\mathrm{d}, \mathrm{e}}$ Yanting Yin, ${ }^{\mathrm{d}, \mathrm{e}}$ Filip Stojcevski, ${ }^{\mathrm{a}}$ and Luke C. Henderson. ${ }^{\mathrm{a} 1}$

a Institute for Frontier Materials, Deakin University, Waurn Ponds, Victoria 3216, Australia.

b CSIRO Manufacturing, Clayton, Victoria, Australia 3168.

${ }^{c}$ Engineering Materials Science, Tampere University, P.O. Box 589, 33014 Tampere, Finland

${ }^{d}$ Flinders Institute for Nanoscale Science and Technology, Flinders University, Adelaide, South Australia 5042,

Australia

e Flinders Microscopy and Microanalysis, College of Science and Engineering, Flinders University, Adelaide,

South Australia 5042, Australia

\section{Supporting Information}

SI-2 Fiber Mechanical Properties

SI-3 Cyclic Voltammograms of Grafted Monomers

SI-5 Synthesis of 4-nitrobenzene diazonium tetrafluoroborate

SI-6 Fragment images from each sample

SI-7 SEM images of post debonded samples from Surfaces 1-5 in PMMA.

\footnotetext{
${ }^{1}$ Corresponding Authors. E-mail: luke.henderson@ deakin.edu.au (Luke Henderson).
} 


\section{Fiber Mechanical Properties}

Fiber mechanical properties were determined using the Favimat Al(Robot2) single fiber tester (Textechno H. Stein, Germany). The process involves using rubber tipped tweezers to extract individual carbon fiber filaments from a $12 \mathrm{k}$ fiber tow ( 75 filaments for each sample set). The average extracted fiber length was between 5-10 centimetres, and were placed in a fiber loading rack whereby the Favimat instrument elongated the fibers at a rate of $10 \mathrm{~mm} / \mathrm{min}$. Upon acoustic initiation, the Favimat can measure Linear fiber density, fiber diameter, elongation, Young's modulus and tensile strength. Tensile load and elongation were within $0.0001 \mathrm{cN}$ and $0.1 \mu \mathrm{m}$, respectively.

A two-tailed Weibull Probability $(\mathrm{P})$ function was then used to process the obtained data. This calculates the combined probability for individual fibers to undergo premature failure respective to that of the other similar fibers tested. This test was performed exclusively on the tensile strength data on this set, and used for the SFFT. The Weibull analysis showed a linear distribution, which denotes minimal variability in fiber quality, regardless of the point of extraction from the fiber tow (See Table S1). This was observed for all fiber sets, and suggests homogenous mechanical properties across the entire fibre bundle. The nomenclature of variables to determine $\mathrm{P}$ is provided in Table $\mathbf{S 1}$ where Equation S1 was used to determine $\mathrm{P}$ after all values were ordered using the median rank method (Equation S2).

$$
\begin{gathered}
P=1-\exp \left[-\left(\frac{\sigma}{\sigma_{0}}\right)^{m}\right] \\
P=\frac{i-0.3}{n+0.4}
\end{gathered}
$$

\section{Equation S1}

Equation S2

Table S1: Nomenclature of values for SFFT and Weibull analysis

\begin{tabular}{cc}
\hline Symbol & Property (Unit) \\
\hline$\sigma_{0}$ & Characteristic fiber stress. (MPa) \\
$\sigma$ & Applied tensile strength. (MPa) \\
$m$ & Weibull shape parameter/modulus. \\
$n$ & Number of samples run ( $\mathrm{n}=75)$ \\
$i$ & Individual fiber ordered tensile strength rank. \\
\hline
\end{tabular}

Table S2: Weibull Values of $\sigma$ and $m$, and tensile and modulus data for each of the treated fibres.

\begin{tabular}{ccccc}
\hline Surface & $\mathbf{m}$ & $\boldsymbol{\sigma}$ & $\begin{array}{c}\text { Tensile } \\
\text { Strength } \\
(\mathbf{G P a})\end{array}$ & $\begin{array}{c}\text { Tensile } \\
\text { Modulus } \\
(\text { GPA) }\end{array}$ \\
\hline Pristine & 3.90 & 3.64 & $3.13 \pm 0.05$ & $240 \pm 5$ \\
1 & 4.03 & 3.46 & $3.13 \pm 0.09$ & $233.6 \pm 2.39$ \\
2 & 4.82 & 3.84 & $3.52 \pm 0.09$ & $253.1 \pm 2.61$ \\
3 & 4.46 & 4.09 & $3.74 \pm 0.11$ & $268.8 \pm 1.417$ \\
4 & 3.62 & 4.13 & $3.68 \pm 0.11$ & $269.7 \pm 1.38$ \\
5 & 3.89 & 4.15 & $4.05 \pm 0.09$ & $267.7 \pm 3.08$ \\
6 & 5.01 & 4.71 & $3.52 \pm 0.1$ & $266 \pm 1.67$ \\
\hline
\end{tabular}




\section{Cyclic Voltammograms of Grafted Monomers}

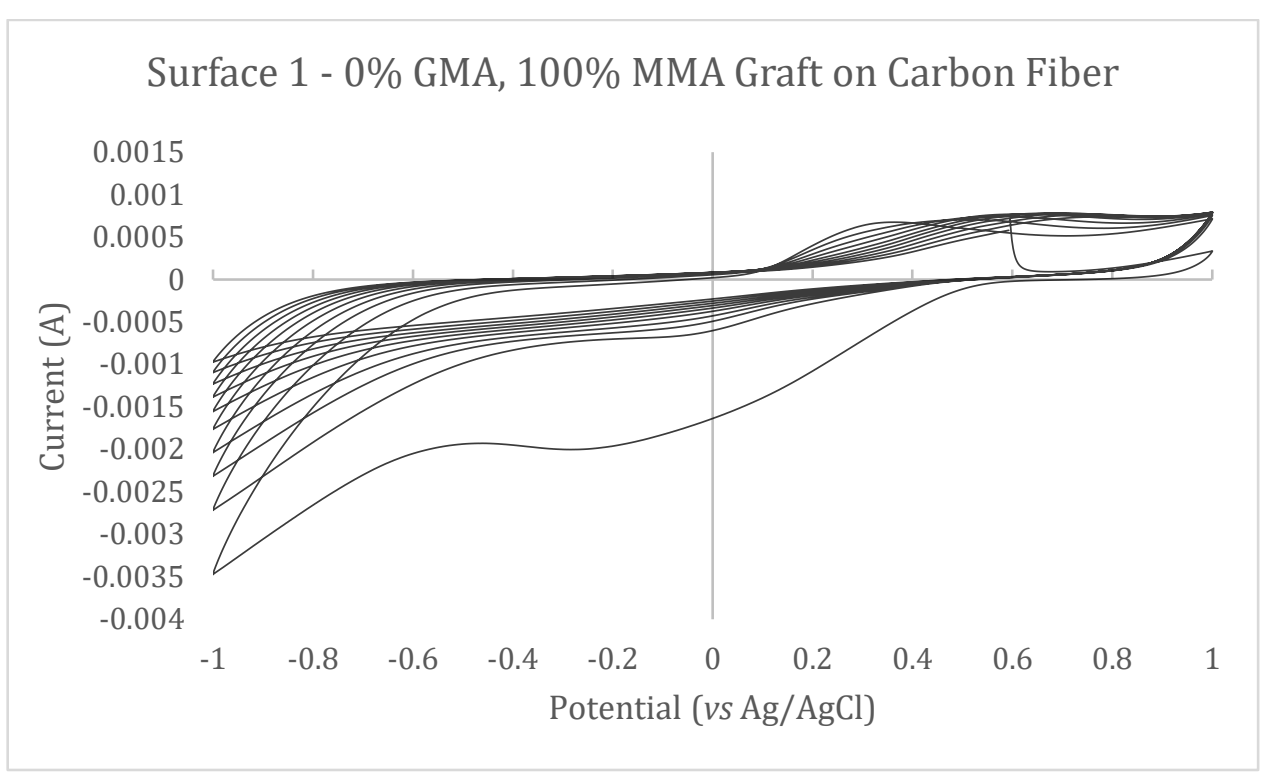

Figure S1: Cyclic voltammetry (CV) sweep of pristine carbon fibres submerged in monomer grafting solution (O M GMA, 1.0 M MMA).

Surface 2 - 25\% GMA, 75\% MMA Graft on Carbon Fiber

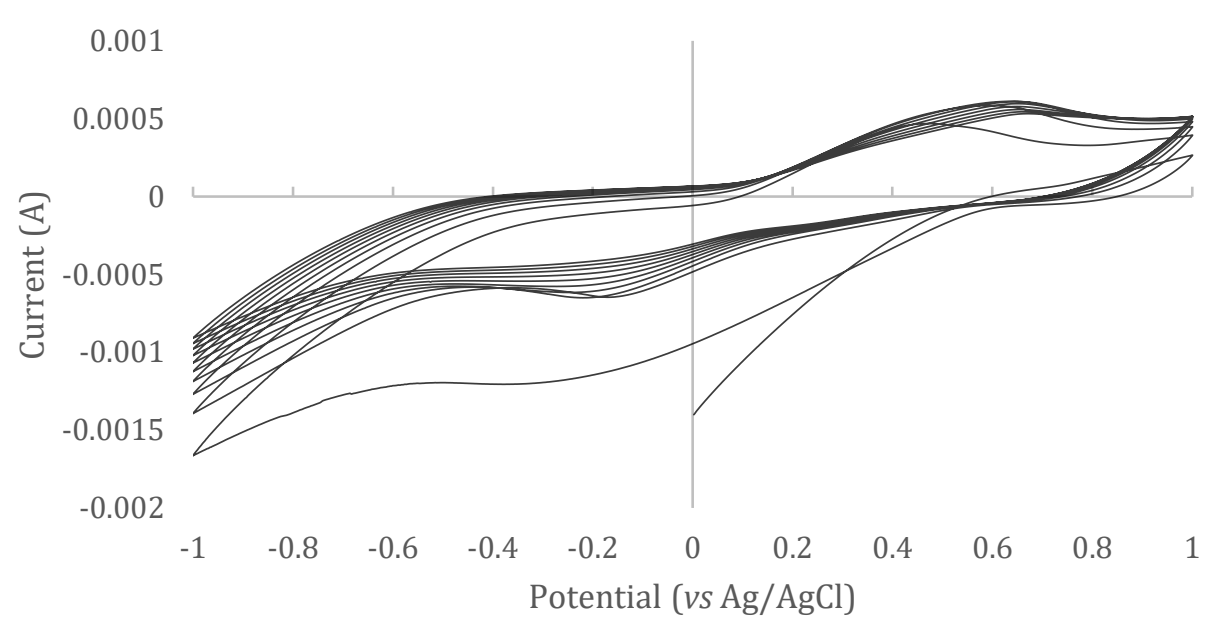

Figure S2: Cyclic voltammetry (CV) sweep of pristine carbon fibres submerged in monomer grafting solution (0.25 M GMA, 0.75 M MMA). 
Surface 3 - 50\% GMA, 50\% MMA Graft on Carbon Fiber

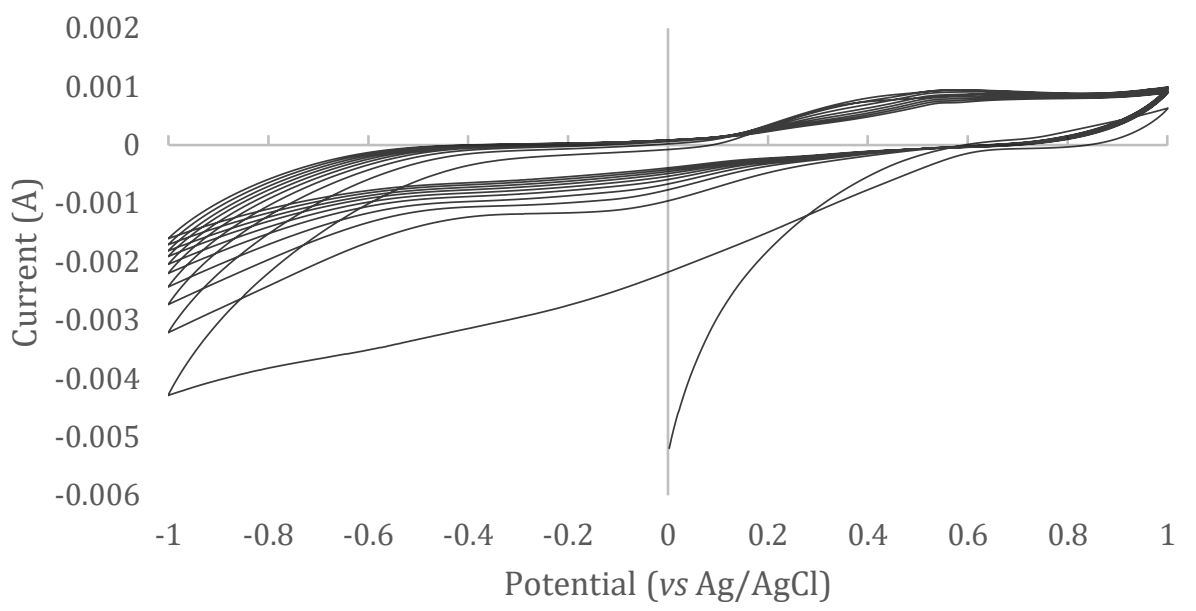

Figure S3: Cyclic voltammetry (CV) sweep of pristine carbon fibres submerged in monomer grafting solution (0.5 M GMA, 0.5 M MMA).

Surface 4 - 75\% GMA, 25\% MMA Graft on Carbon Fiber

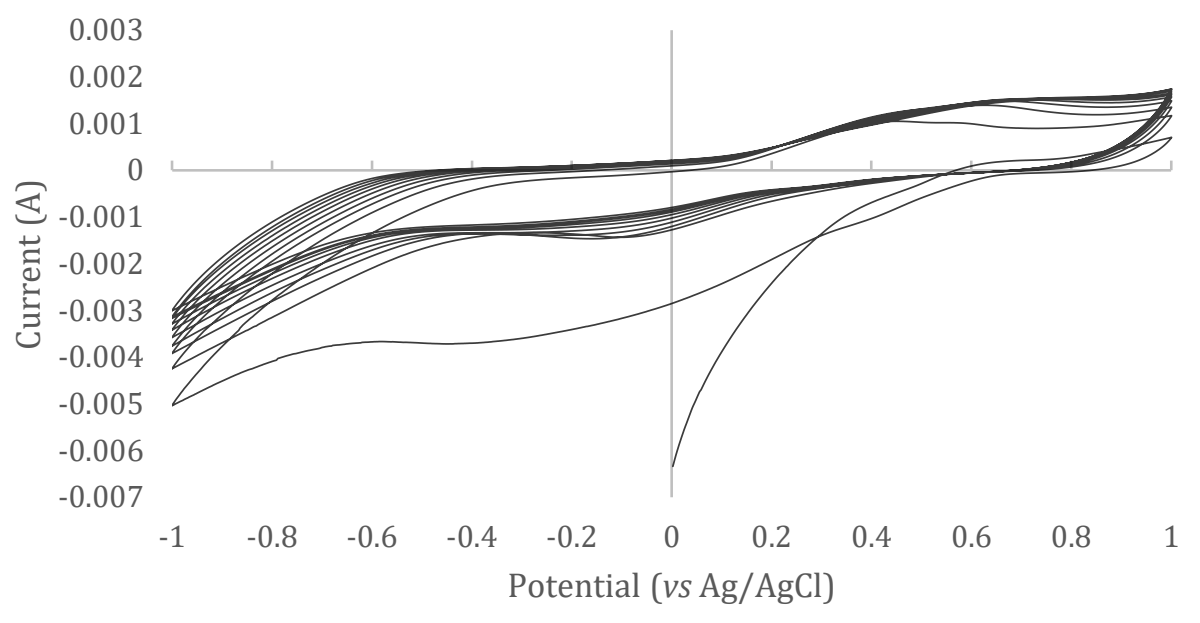

Figure S4: Cyclic voltammetry (CV) sweep of pristine carbon fibres submerged in monomer grafting solution (0.75 M GMA, 0.25 M MMA). 


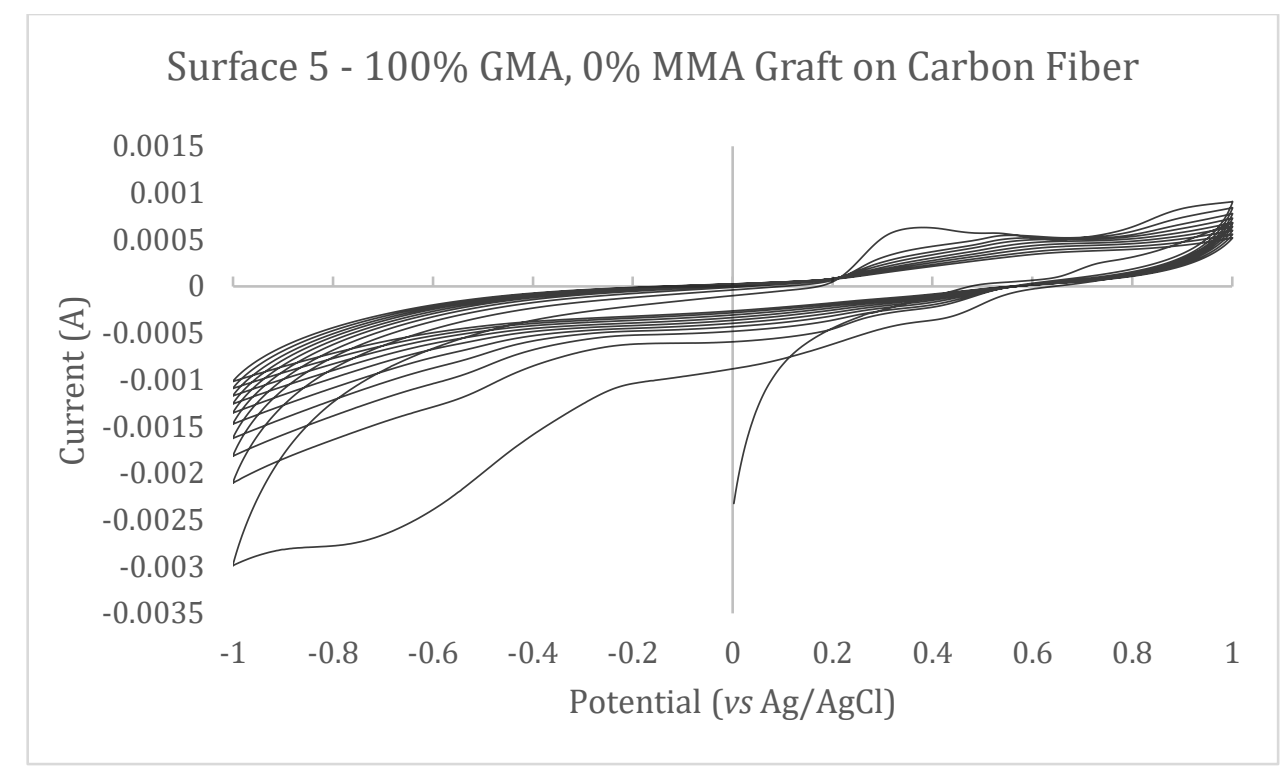

Figure S5: Cyclic voltammetry (CV) sweep of pristine carbon fibres submerged in monomer grafting solution (1.0 M GMA, O M MMA).

\section{Synthesis of 4-nitrobenzene diazonium tetrafluoroborate}

A mixture of anhydrous MeCN (3mL) was charged with NOBF4 (507 mg, $4.3 \mathrm{mmol})$ and cooled to $41^{\circ} \mathrm{C}$ in a two-necked round bottom flask under inert atmosphere. 4-nitro aniline (500 mg, $\left.3.62 \mathrm{mmol}\right)$ was then added to the reaction mixture and stirred for 30 minutes, followed by warming to room temperature for an hour. Approximately $10 \mathrm{~mL}$ of ice-cold diethyl ether was injected into the mixture and afforded the diazonium salt precipitate as a light yellow powder (782 mg, $3.30 \mathrm{mmol}, 91 \%)$, and was then filtered and collected using a Hirsch funnel and filter flask in-vacuo. ${ }^{1} \mathrm{H} \mathrm{NMR}(400 \mathrm{MHz}$, d6-DMSO) $8.70(\mathrm{~d}, 2 \mathrm{H}, \mathrm{J}=8.0 \mathrm{~Hz}), 8.91(\mathrm{~d}, 2 \mathrm{H}, \mathrm{J}=8.0 \mathrm{~Hz})$, Matched literature value [1]. 


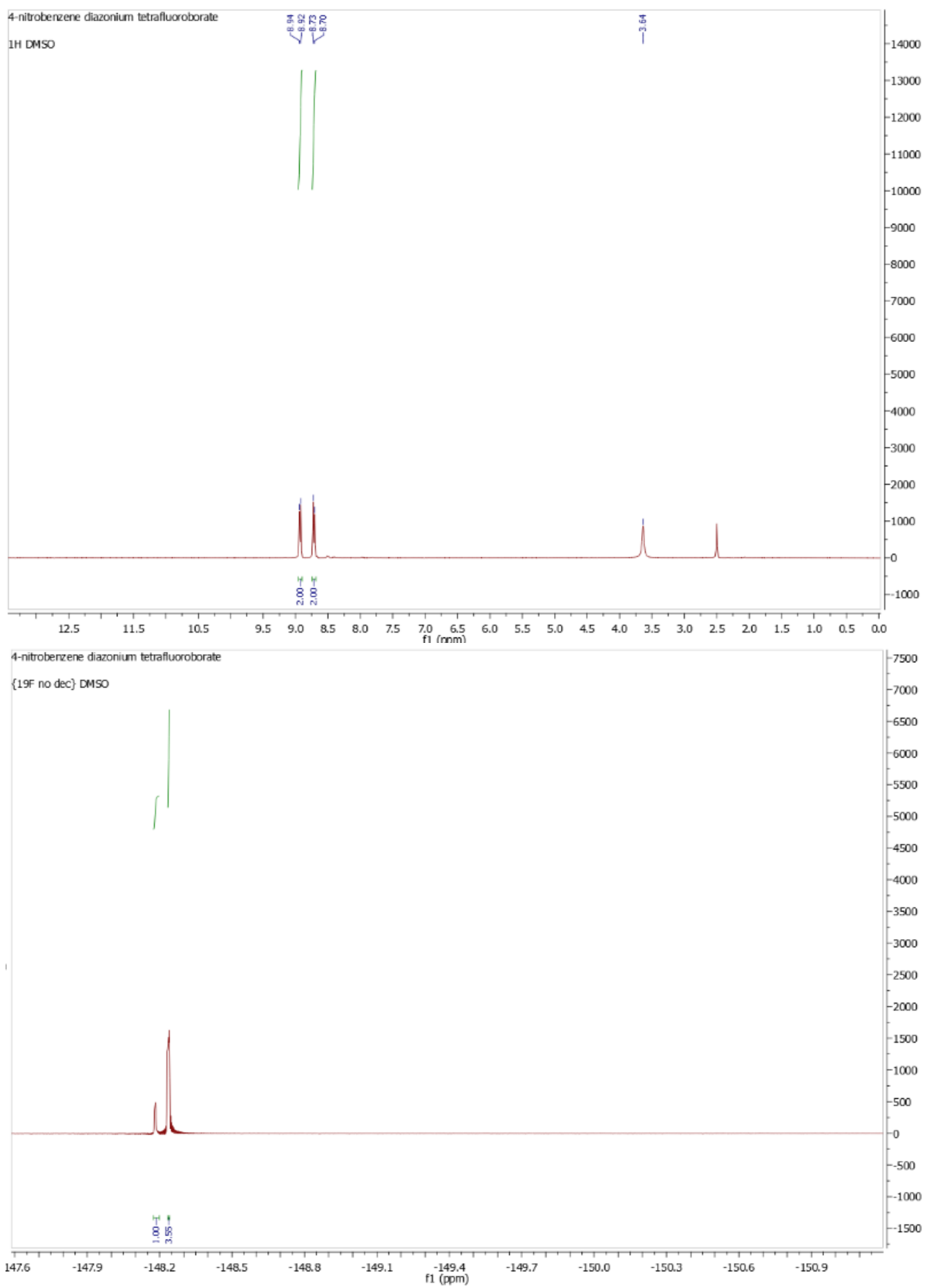

Figure S6: (top) ${ }^{1} \mathrm{H}$ and (bottom) ${ }^{19} \mathrm{~F}$ NMR spectrum of synthesized 4-nitrobenzene diazonium tetrafluoroborate.

Microscope images of modified fibres under SFFT 


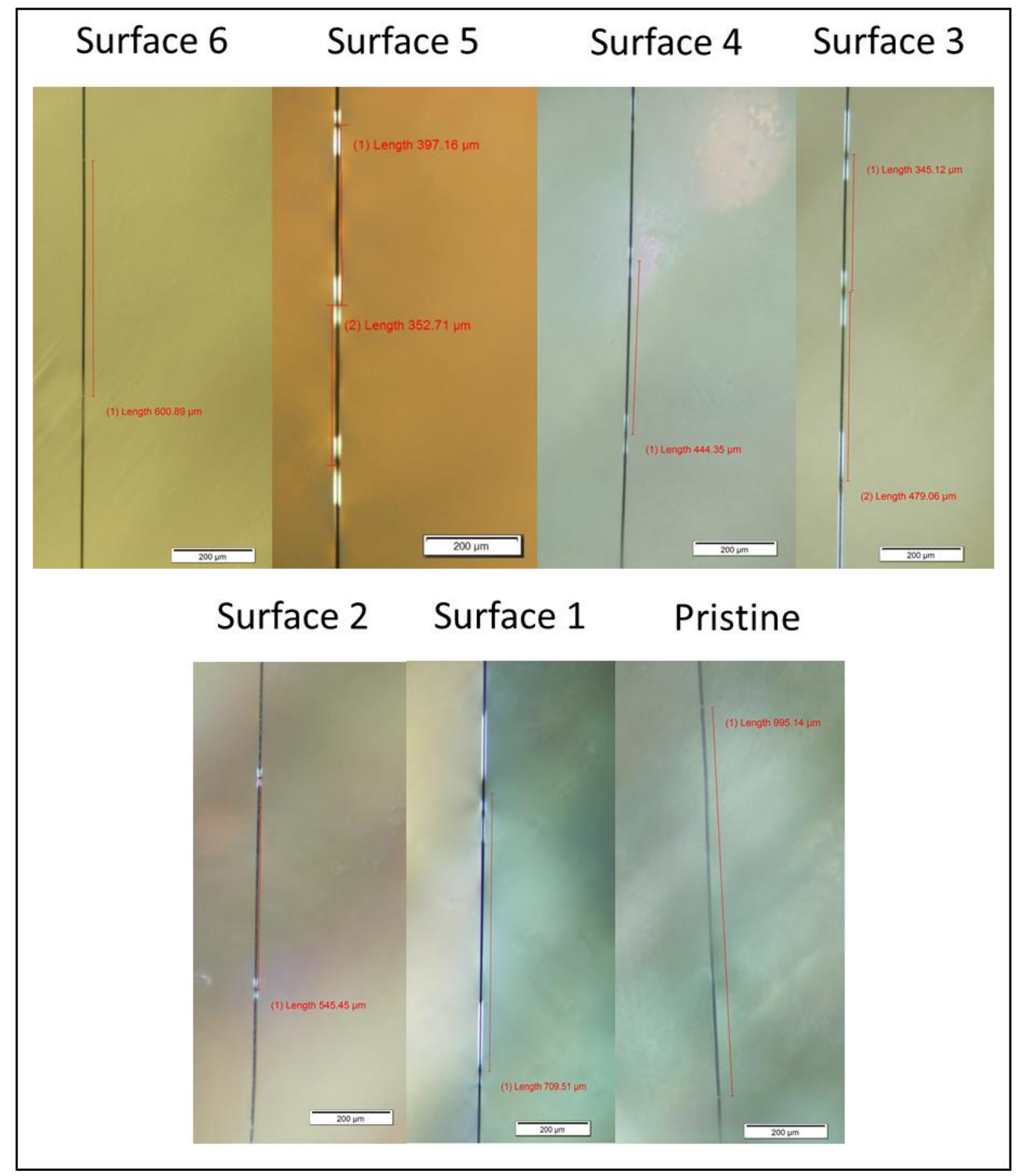

Figure S7: Microscopy images of fractured surface modified carbon fibres in epoxy resin, observed during for the Single Fibre Fragmentation Test (SFFT). Surfaces 1-5 were samples treated with 0.25 $M$ decrements of MMA and a $0.25 \mathrm{M}$ increments of GMA, respectively (i.e. Surface $1=1.0 \mathrm{M} M M A$ and 0 M GMA, Surface $2=0.75$ M MMA and 0.25 M GMA, etc.). 


\section{SEM images of post debonded samples from Surfaces 1-5 in PMMA.}

\section{Surface 1 (1.0 M MMA / 0 M GMA)}

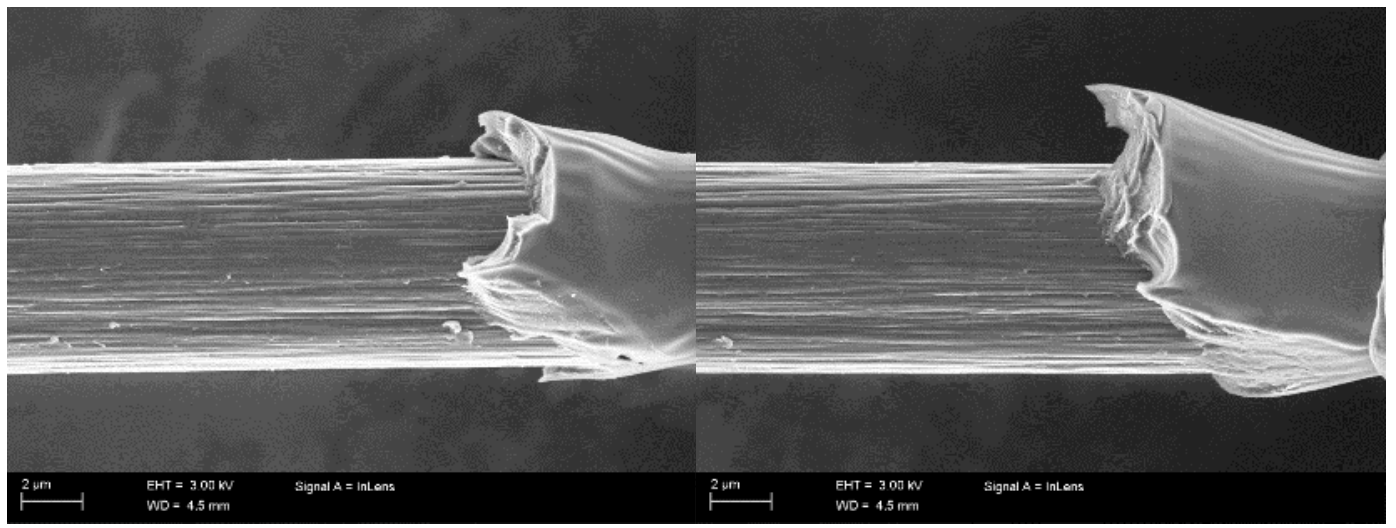

Figure S8: Scanning Electron Microscopy (SEM) images of carbon fibres treated with 1.0 M MMA / 0 M GMA (Surface 1) after the single fibre debond test in PMMA thermoplastic.

\section{Surface 2 (0.75 M MMA / 0.25 M GMA)}

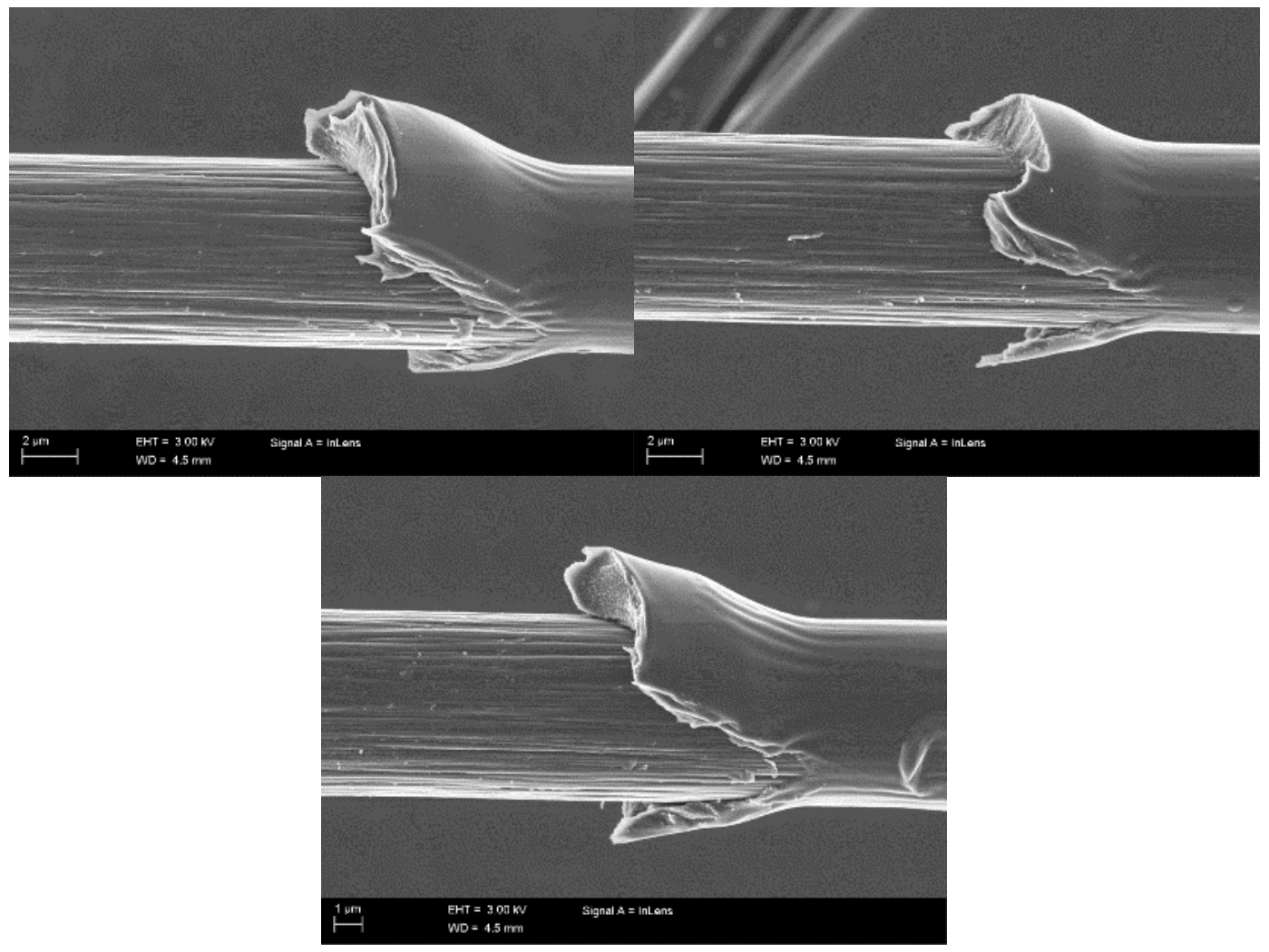

Figure S9: Scanning Electron Microscopy (SEM) images of carbon fibres treated with $0.75 \mathrm{M} M \mathrm{MA}$ / 0.25 M GMA (Surface 2) after the single fibre debond test in PMMA thermoplastic. 
Surface 3 (0.5 M MMA / 0.5 M GMA)

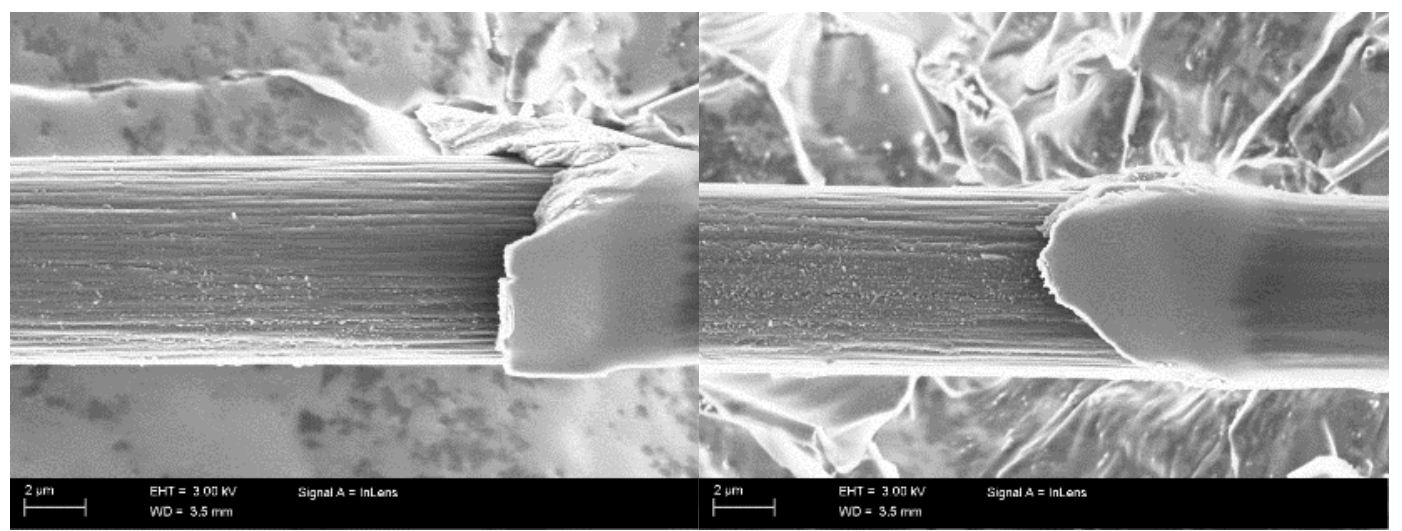

Figure S10: Scanning Electron Microscopy (SEM) images of carbon fibres treated with 0.5 M MMA / 0.5 M GMA (Surface 3) after the single fibre debond test in PMMA thermoplastic.

\section{Surface 4 (0.25 M MMA / 0.75 M GMA)}

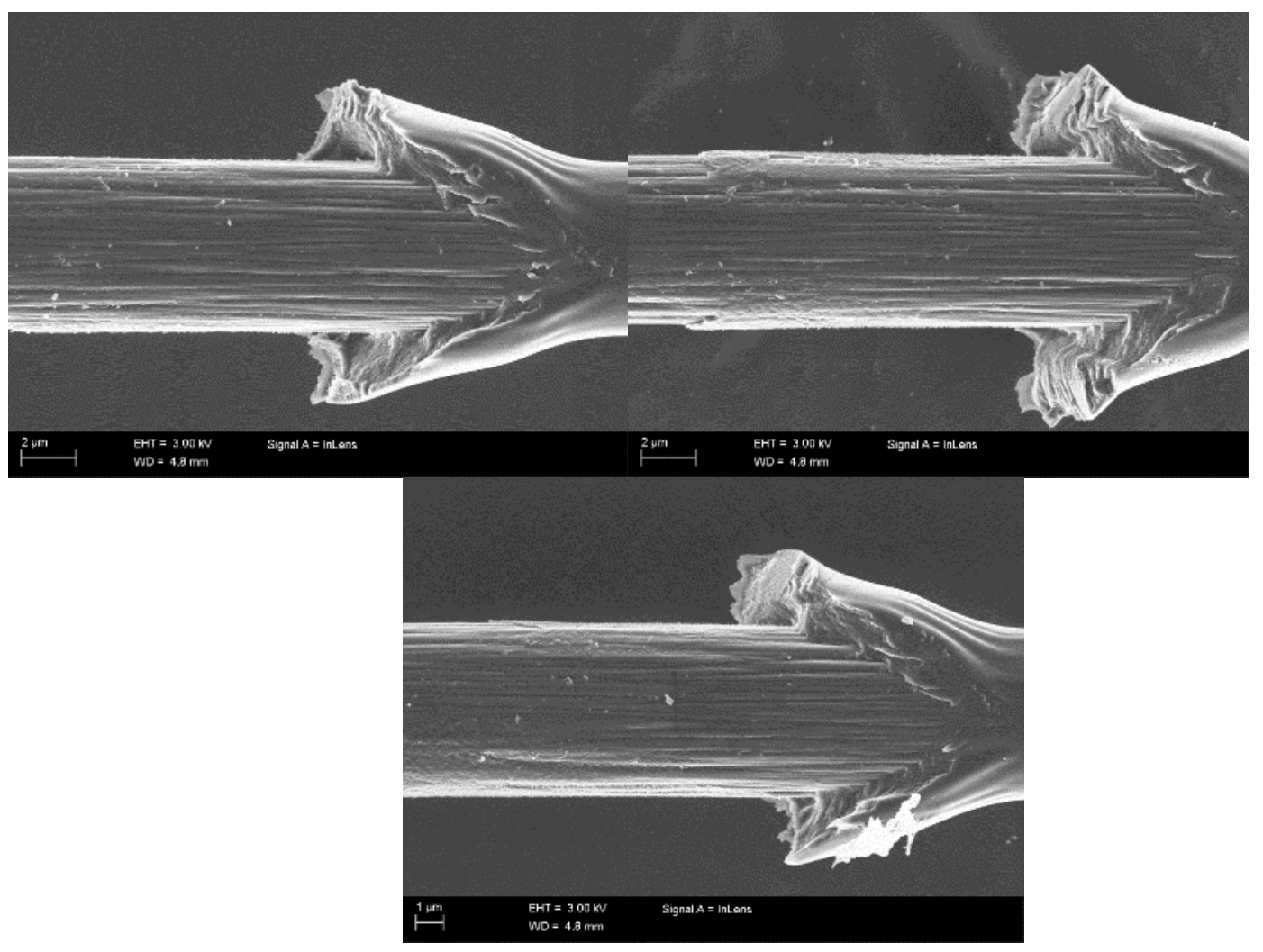

Figure S11: Scanning Electron Microscopy (SEM) images of carbon fibres treated with 0.25 M MMA / 0.75 M GMA (Surface 4) after the single fibre debond test in PMMA thermoplastic. 
Surface 5 (0 M MMA / 1.0 M GMA)

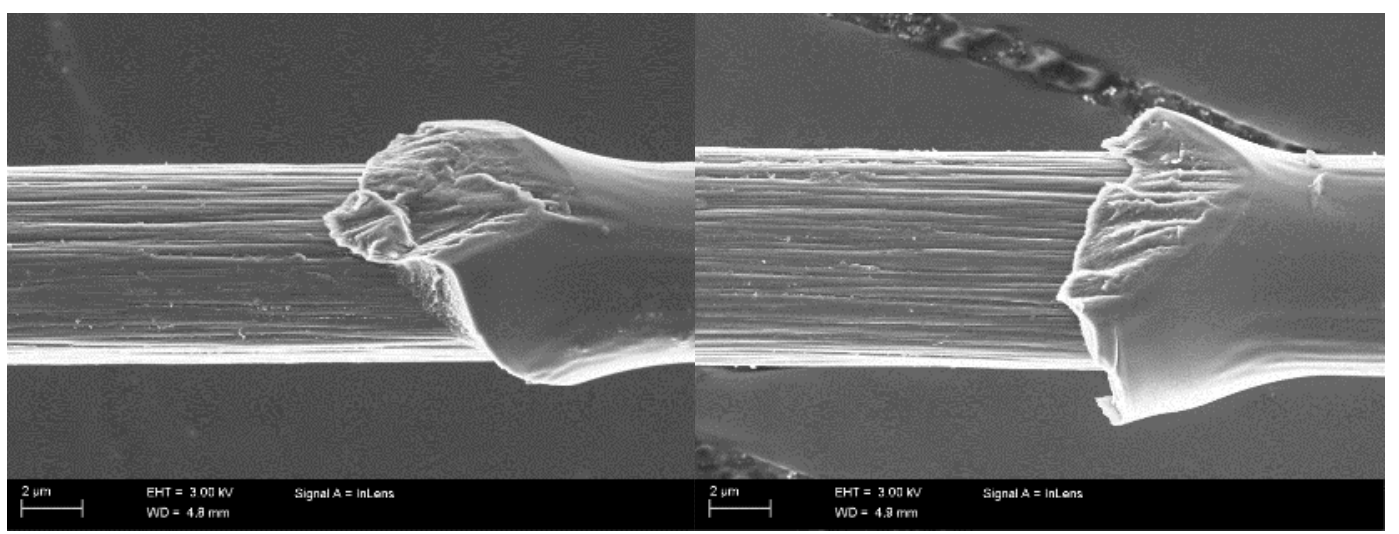

Figure S12: Scanning Electron Microscopy (SEM) images of carbon fibres treated with O M MMA / 1.0 M GMA (Surface 5) after the single fibre debond test in PMMA thermoplastic.

[1] Z.Y. Tang, Y. Zhang, T. Wang, W. Wang, Rhodium(I)-Catalyzed Synthesis of Aryltriethoxysilanes from Arenediazonium Tosylate Salts with Triethoxysilane, Synlett 2010(05) (2010) 804-808. 